\title{
Antagonism of ghrelin receptor reduces food intake and body weight gain in mice
}

\author{
A Asakawa, A Inui, T Kaga, G Katsuura, M Fujimiya, M A Fujino, M Kasuga
}

Gut 2003;52:947-952

See end of article for authors' affiliations

\section{Correspondence to:}

Dr A Inui, Division of

Diabetes, Digestive and

Kidney Diseases,

Department of Clinical

Molecular Medicine, Kobe

University Graduate School

of Medicine, 7-5-2

Kusunoki-cho, Chuo-ku,

Kobe 650-0017, Japan

inui@med.kobe-u.ac.jp

Accepted for publication

8 January 2003

\begin{abstract}
Background and aims: Ghrelin, an endogenous ligand for growth hormone secretagogue receptor (GHS-R), is an appetite stimulatory signal from the stomach with structural resemblance to motilin. We examined the effects of the gastric peptide ghrelin and GHS-R antagonists on energy balance and glycaemic control in mice.

Materials and methods: Body weight, fat mass, glucose, insulin, and gene expression of leptin, adiponectin, and resistin in white adipose tissue (WAT) were measured after repeated administrations of ghrelin under a high fat diet. Gastric ghrelin gene expression was assessed by northern blot analysis. Energy intake and gastric emptying were measured after administration of GHS-R antagonists. Repeated administration of GHS-R antagonist was continued for six days in ob/ob obese mice.

Results: Ghrelin induced remarkable adiposity and worsened glycaemic control under a high fat diet. Pair feeding inhibited this effect. Ghrelin elevated leptin mRNA expression and reduced resistin mRNA expression. Gastric ghrelin mRNA expression during fasting was increased by a high fat diet. GHS-R antagonists decreased energy intake in lean mice, in mice with diet induced obesity, and in ob/ob obese mice; it also reduced the rate of gastric emptying. Repeated administration of GHS-R antagonist decreased body weight gain and improved glycaemic control in ob/ob obese mice.

Conclusions: Ghrelin appears to be closely related to excess weight gain, adiposity, and insulin resistance, particularly under a high fat diet and in the dynamic stage. Gastric peptide ghrelin and GHS-R may be promising therapeutic targets not only for anorexia-cachexia but also for obesity and type 2 diabetes, which are becoming increasingly prevalent worldwide.
\end{abstract}

G hrelin, a 28 amino acid peptide with an n-octanoyl modification on Ser 3, was recently identified in the stomach as an endogenous ligand for growth hormone secretagogue receptor (GHS-R). ${ }^{1}$ The ghrelin gene is highly expressed in the stomach, and ghrelin circulates in human blood at a considerable plasma concentration. ${ }^{1}$ This gut peptide with structural resemblance to motilin is involved in the regulation of growth hormone $(\mathrm{GH})$ secretion, energy balance, gastric motility, and anxiety. ${ }^{1-7}$ Previous studies have shown that administered ghrelin induces body weight gain and adiposity in rodents by promoting food intake and decreasing fat utilisation or energy expenditure. ${ }^{2-5}$ Serum ghrelin concentrations are increased by fasting and are reduced by refeeding or oral and intravenous glucose administration. ${ }^{8} 9$ In addition, ghrelin as well as synthetic growth hormone secretagogues, have been reported to stimulate feeding in humans. ${ }^{26}$ These findings indicate that the gastric peptide ghrelin and GHS-R may be involved in the pathophysiology of obesity associated with an increased risk of diabetes, hypertension, hyperlipidaemia, osteoarthritis, and certain forms of cancer. Therefore, in the present study, we examined the role of ghrelin in diet induced obesity as well as the therapeutic potential of GHS-R antagonist in murine models of obesity.

\section{METHODS}

\section{Animal experiments}

Male mice of the ddy strain (34-37 g; Japan Slc, Shizuoka, Japan) and obese (ob/ob) C57BL/6J mice (68-74 g; Shionogi Co. Ltd, Shiga, Japan) were used. They were individually housed in a regulated environment $\left(22 \pm 2^{\circ} \mathrm{C}, 55 \pm 10 \%\right.$ humidity, 12:12 hour light:dark cycle with lights on at 7:00 am). Mice received a standard diet containing $12 \%$ of total energy as fat or a high fat diet containing $45 \%$ of total energy as fat (Clea Japan Inc., Tokyo, Japan). Food and water were available ad libitum except as otherwise indicated. All experiments were approved by our university animal care committee. [D-Lys-3]GHRP-6, [D-Arg-1, D-Phe-5, D-Trp-7, 9, Leu-11] substance P, and rat ghrelin were purchased from Bachem California Inc. (Torrance, California, USA), Neosystem (Strasbourg, France), and Peptide Institute (Osaka, Japan), respectively. Just before administration, each drug was diluted in $4 \mu \mathrm{l}$ of artificial cerebrospinal fluid for intra-third cerebroventricular (ICV) injection or in $100 \mu \mathrm{l}$ of physiological saline for intraperitoneal injection. Doses of GHS-R antagonists were determined from our preliminary experiments on food intake and affinities for GHS- R. ${ }^{10-12}$ Results are expressed as means (SEM). Analysis of variance (ANOVA) followed by Bonferroni's $t$ test were used to assess differences among groups: $\mathrm{p}<0.05$ was considered to be statistically significant.

\section{ICV substance application}

For ICV injection, mice were anaesthetised with sodium pentobarbital (80-85 mg/kg intraperitoneally) and placed in a stereotaxic instrument seven days before the experiments. A hole was made in each skull using a needle inserted $0.9 \mathrm{~mm}$ lateral to the central suture and $0.9 \mathrm{~mm}$ posterior to the bregma. A 24 gauge cannula bevelled at one end over a distance of $3 \mathrm{~mm}$ was implanted into the third cerebral ventricle for ICV injection. The cannula was fixed to the skull with dental cement and capped with silicon without an obtruder. A 27 gauge injection insert was attached to a microsyringe by PE-20 tubing.

Abbreviations: AGRP, agouti related protein; $A R C$, arcuate nucleus; FFA, free fatty acids; $G H$, growth hormone; GHRP, growth hormone releasing peptide; GHS-R, growth hormone secretagogue receptor; ICV, intra-third cerebroventricular(ly); NPY, neuropeptide Y; WAT, white adipose tissue. 
Table 1 Effects of ghrelin administered intraperitoneally $(3 \mathrm{nmol} /$ mouse every 12 hours for five days) on calorie intake, epididymal fat mass, gastrocnemius muscle, and blood glucose, insulin, cholesterol, triglycerides, and free fatty acid concentrations in lean mice under a high fat diet

\begin{tabular}{|c|c|c|c|}
\hline & LF, saline & $\mathrm{HF}$, saline & $\mathrm{HF}$, ghrelin \\
\hline Calorie intake (kcal/day) & $18.83 \quad(1.055)$ & 23.22 (1.329) & $25.94(2.562)^{*}$ \\
\hline Fat pad mass (g) & $0.533(0.049)$ & $0.797(0.095)$ & $1.202(0.175)^{* *} \dagger$ \\
\hline Skeletal musde (g) & $0.337(0.016)$ & $0.353(0.010)$ & $0.340(0.005)$ \\
\hline Glucose (mmol/l) & $7.899(0.476)$ & $8.393(0.825)$ & 8.909 (0.498) \\
\hline Insulin (pmol/I) & $135.0 \quad(20.10)$ & $177.5 \quad$ (13.05) & $378.0 \quad(141.8)^{*}$ \\
\hline Cholesterol (mmol/l) & $3.742(0.337)$ & $5.568(0.497)$ & $5.813(0.509)$ * * \\
\hline Triglycerides (mmol//l) & $0.347(0.032)$ & $0.305(0.039)$ & $0.371(0.090)$ \\
\hline Free fatty acids (meq/l) & $1.467(0.050)$ & $1.623(0.100)$ & $1.636(0.047)$ \\
\hline
\end{tabular}

Results are expressed as mean (SEM)

LF and HF indicate a standard diet and a high fat diet, respectively.

${ }^{*} p<0.05,{ }^{*} p<0.01$ between saline treated mice fed a standard diet and ghrelin treated mice fed a high fat diet.

$t p<0.05$ between saline treated mice fed a high fat diet and ghrelin treated mice fed a high fat diet.

\section{Feeding tests}

Experiments were started at 10:00 am. Before feeding tests, mice were food deprived for 16 hours with free access to water, except for the experiment of the effect of coadministration of [D-Lys-3]-GHRP-6 and ghrelin on food intake, in which mice were given free access to food and water. Food intake was measured by subtracting uneaten food from the initially premeasured food at 20 minutes, one, two, and four hours after administration.

\section{RNA isolation and northern blot analysis}

RNA was isolated from the stomach and epididymal fat using the RNeasy Mini Kit (Qiagen, Tokyo, Japan). Total RNA was denatured with formaldehyde, electrophoresed in $1 \%$ agarose gel, and blotted onto a Hybond $\mathrm{N}^{+}$membrane. The membranes were hybridised with a fluoresceine labelled cDNA probe. The total integrated densities of hybridisation signals were determined by densitometry (Amersham Pharmacia Biotech AB, Uppsala, Sweden). Data were normalised to glyceraldehyde 3-phosphate dehydrogenase mRNA abundance and expressed as a percentage of controls.

\section{Ghrelin gene expression}

Lean mice received a standard diet containing $12 \%$ of total energy as fat or a high fat diet containing $45 \%$ of total energy as fat for two weeks. Mice were fasted for eight hours before being killed by cervical dislocation. Immediately after, stomachs were removed, frozen on dry ice, and stored at $-80^{\circ} \mathrm{C}$ until preparation of northern blots.

\section{Gastric emptying}

Before the gastric emptying experiments, mice were food deprived for 16 hours with free access to water. Fasted mice had free access to preweighed pellets for one hour and were then administered [D-Lys-3]-GHRP-6. Mice were deprived of food again for one or two hours after injection. Food intake was measured by weighing uneaten pellets. Mice were killed by cervical dislocation two or three hours after the start of the experiments. Immediately after the stomach was exposed by laparotomy, quickly ligated at both the pylorus and cardia, removed, and the dry content was weighed. Gastric emptying was calculated according to the following formula:

gastric emptying $(\%)=(1-$ (dry weight of food recovered from the stomach/weight of food intake)) $\times$ 100.

\section{Anxiety tests}

Anxiety was assessed in the standard elevated plus maze, $50 \mathrm{~cm}$ above the ground..$^{13}$ The four arms were $27 \mathrm{~cm}$ long and $6 \mathrm{~cm}$ wide. Two opposing arms were enclosed by walls $15 \mathrm{~cm}$ high (closed arms) while the other arms were devoid of walls (open arms). Each mouse was placed in the centre of the maze facing one of the enclosed arms 10 minutes after injection. The cumulative time spent in each arm and the number of entries into the open or closed arms were recorded during a five minute test session. The time spent in the open arms was expressed as a percentage of total entry time (100×open/ open + closed) and the number of entries in the open arms was expressed as a percentage of the total number of entries (100×open/total entries).

\section{Repeated injection}

Repeated intraperitoneal injections were continued for five days in lean mice under a high fat diet or a standard diet, and for six days in lean and $o b / o b$ obese mice under a standard diet, respectively. Mice were injected daily at 7:00 am and 19:00 pm. Food intake and body weight were measured daily. For pair feeding studies, a pair fed group experiment was initiated one day after the pair group to match food intake. Serum was separated from blood obtained from the orbital sinus under ether anaesthesia at the end of the experiment (eight hours after removal of food and the final intraperitoneal injection). Mice were killed by cervical dislocation. Immediately after, the epididymal fat pad mass assessed as white adipose tissue (WAT) and the gastrocnemius muscle were removed and weighed. Blood glucose was measured by the glucose oxidase method. Serum insulin and free fatty acids (FFA) were measured by enzyme immunoassay and an enzymatic method (Eiken Chemical Co., Ltd, Tokyo, Japan), respectively. Serum triglycerides and total cholesterol were measured by an enzymatic method (Wako Pure Chemical Industries, Ltd, Tokyo, Japan).

\section{RESULTS}

We first examined the effects of repeated administration of ghrelin on body weight gain and glycaemic control under a high fat diet. Intraperitoneal injection of ghrelin twice daily for five days tended to increase body weight compared with saline treated mice fed a high fat diet. Body weight of saline treated mice fed a standard diet, saline treated mice fed a high fat diet, and ghrelin treated mice fed a high fat diet increased by $0.44(0.13), 0.60(0.12)$, and $0.92(0.18) \mathrm{g} /$ day, respectively. There were significant differences in fat pad mass both between saline treated mice fed a standard diet and ghrelin treated mice fed a high fat diet, and also between saline treated mice fed a high fat diet and ghrelin treated mice fed a high fat diet (table 1). Skeletal muscle did not show an increase in weight. Serum cholesterol and insulin levels were also increased, accompanied by a moderate increase in blood glucose concentrations. We then assessed mRNA levels of leptin, adiponectin, and resistin in WAT. Repeated ghrelin injections reduced resistin mRNA expression in WAT (fig lA). Gene expression of leptin and adiponectin in ghrelin treated 

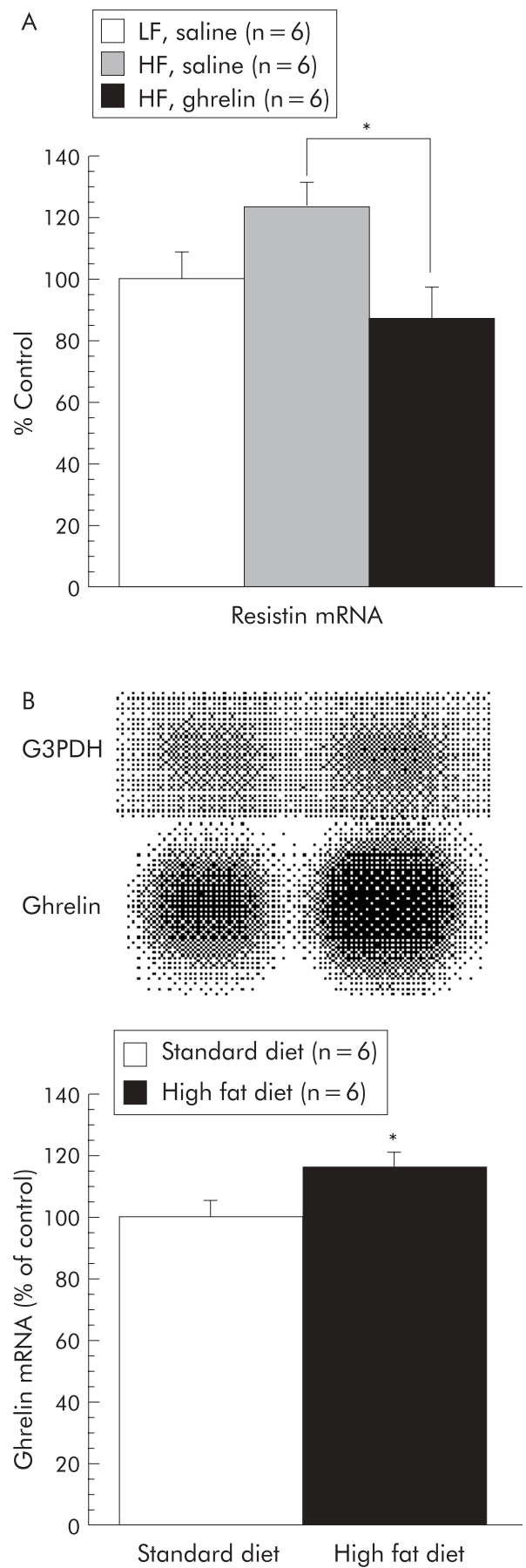

Figure 1 (A) Chronic effects of ghrelin administered intraperitoneally ( $3 \mathrm{nmol} /$ mouse every 12 hours for five days) on resistin gene expression in the epididymal fat mass under a high fat (HF) diet, as assessed by northern blot analysis, expressed as a percentage of physiological saline treated controls under a standard (LF) diet. Results are expressed as mean (SEM): $n$ indicates the number of mice used, ${ }^{*} p<0.05$ between saline treated mice fed a high fat diet and ghrelin treated mice fed a high fat diet. (B) Stimulatory effects of a high fat diet for two weeks on ghrelin gene expression in the stomach of food deprived mice, as assessed by northern blot analysis, expressed as a percentage of standard diet fed controls. (Top) A representative northern blot analysis showing gastric ghrelin mRNA during fasting after a high fat diet for two weeks; * $p<0.05$ compared with the control group by Bonferroni's $t$ test. G3PDH, glyceraldehyde 3-phosphate dehydrogenase.

mice fed a high fat diet was increased by $71 \%$ and 3\%, respectively, compared with saline treated mice fed a high fat diet; however, neither reached statistical significance. Comparison with pair fed controls confirmed that ghrelin had no significant effects on body weight gain $(0.15$ (0.09) ( $3 \mathrm{nmol}) v$ $0.17(0.09) \mathrm{g} /$ day (control); $\mathrm{n}=5)$, fat pad mass $(0.53(0.02) v$ 0.51 (0.06) g (control) or blood glucose concentrations $(6.82$ (0.31) v $7.85(0.29) \mathrm{mmol} / \mathrm{l}$ (control). Furthermore, we assessed ghrelin mRNA expression under a high fat diet containing $45 \%$ of total energy as fat. A high fat diet for two weeks significantly increased ghrelin gene expression in the stomach of food deprived mice compared with a standard diet (fig 1B). On the other hand, a high fat diet showed a tendency to decrease ghrelin gene expression in the fed state compared with a standard diet, although this effect failed to reach statistical significance $(62.0(8.53) \%$ of control; $n=5)$.

We determined whether GHS-R antagonists would influence energy balance. We first administered the GHS-R antagonist [D-Lys-3]-GHRP-6 IP to mice. As shown in fig 2A, [D-Lys-3]-GHRP-6 significantly decreased food intake in a dose related manner. We also investigated whether centrally administered [D-Lys-3]-GHRP-6 has similar effects. ICV as well as intraperitoneally administered [D-Lys-3]-GHRP-6 produced a potent decrease in feeding behaviour (fig 2B). To evaluate the possibility that ghrelin acts through GHS-R in the brain, we examined the effects of simultaneous administration of ghrelin and [D-Lys-3]- GHRP-6 on food intake. ICV administered [D-Lys-3]-GHRP-6 abolished the stimulatory effects on feeding induced by intraperitoneal injection of ghrelin (fig 2C). We next examined the effect of intraperitoneal injection of [D-Lys-3]-GHRP-6 on gastric emptying rate. Peripherally administered [D-Lys-3]-GHRP-6 produced a significant decrease in the gastric emptying rate one hour after administration (fig 2D). No gross behavioural changes were observed after [D-Lys-3]-GHRP-6 administration. In anxiety tests, there were no significant differences in the percentage of total time spent in the open arms (16.3 (10.1) (200 nmol) $v$ $13.8(4.92) \%$ (control); $n=5)$ and the total number of entries into the open arms (20.6 (7.18) v 16.7 (5.75)\% (control)) between control and [D-Lys-3]-GHRP-6 treated animals. We also examined the effect of another GHS-R antagonist [D-Arg-1, D-Phe-5, D-Trp-7, 9, Leu- 11] substance P (L756,867 ) on feeding in food deprived mice. Peripherally administered [D- Arg-1, D-Phe-5, D-Trp-7, 9, Leu-11] substance $\mathrm{P}$ as well as [D-Lys-3]-GHRP-6 significantly decreased food intake in a dose dependent manner (fig 2E). Moreover, we examined the effect of [D-Lys-3]-GHRP-6 in mice rendered obese by a high fat diet. Intraperitoneal administration of [D-Lys-3]-GHRP-6 potently decreased food intake, leading to decreased body weight gain (fig $2 \mathrm{~F}$ ). Seven daily administrations of [D-Lys-3]-GHRP-6 had a tendency to decrease body weight gain $(0.18(0.12)(200 \mathrm{nmol}) v 0.39(0.10) \mathrm{g} /$ day (control); $\mathrm{n}=6)$, fat pad mass $\left(\begin{array}{lllll}1.37 & (0.15) & v & 1.72 & (0.23) \mathrm{g}\end{array}\right.$ (control)), and blood glucose concentrations $(8.85$ (0.39) $v$ $9.28(0.74) \mathrm{mmol} / \mathrm{l}$ (control)) in mice rendered obese by the diet. In addition, comparison with pair fed controls indicated that [D-Lys-3]-GHRP-6 had no significant effects on body weight gain $(0.09(0.09)(200 \mathrm{nmol}) v 0.08(0.05) \mathrm{g} / \mathrm{day}$ (control); $\mathrm{n}=5)$, fat pad mass $(0.49(0.06) v 0.52(0.07) \mathrm{g}$ (control)) or blood glucose concentrations $(7.73$ (0.39) $v 7.07$ (0.41) $\mathrm{mmol} / \mathrm{l}$ (control)) in lean mice.

To gain further insight into the therapeutic potential, we examined whether or not intraperitoneally administered [D-Lys-3]-GHRP-6 produced anorexigenic effects in ob/ob obese mice. [D-Lys-3]-GHRP-6 significantly decreased food intake in $o b / o b$ obese mice as well as in lean mice (fig 3A). Finally, we examined the effects of repeated administration of [D-Lys-3]-GHRP-6 on body weight gain and glycaemic control in $o b / o b$ obese mice. Repeated injections of [D-Lys-3]-GHRP-6 significantly lowered body weight gain and blood glucose concentrations without decreasing muscle weight (fig 3B, table 2). Furthermore, [D-Lys-3]-GHRP-6 treatment significantly reduced FFA levels of $o b / o b$ obese mice by $24 \%$ compared with 

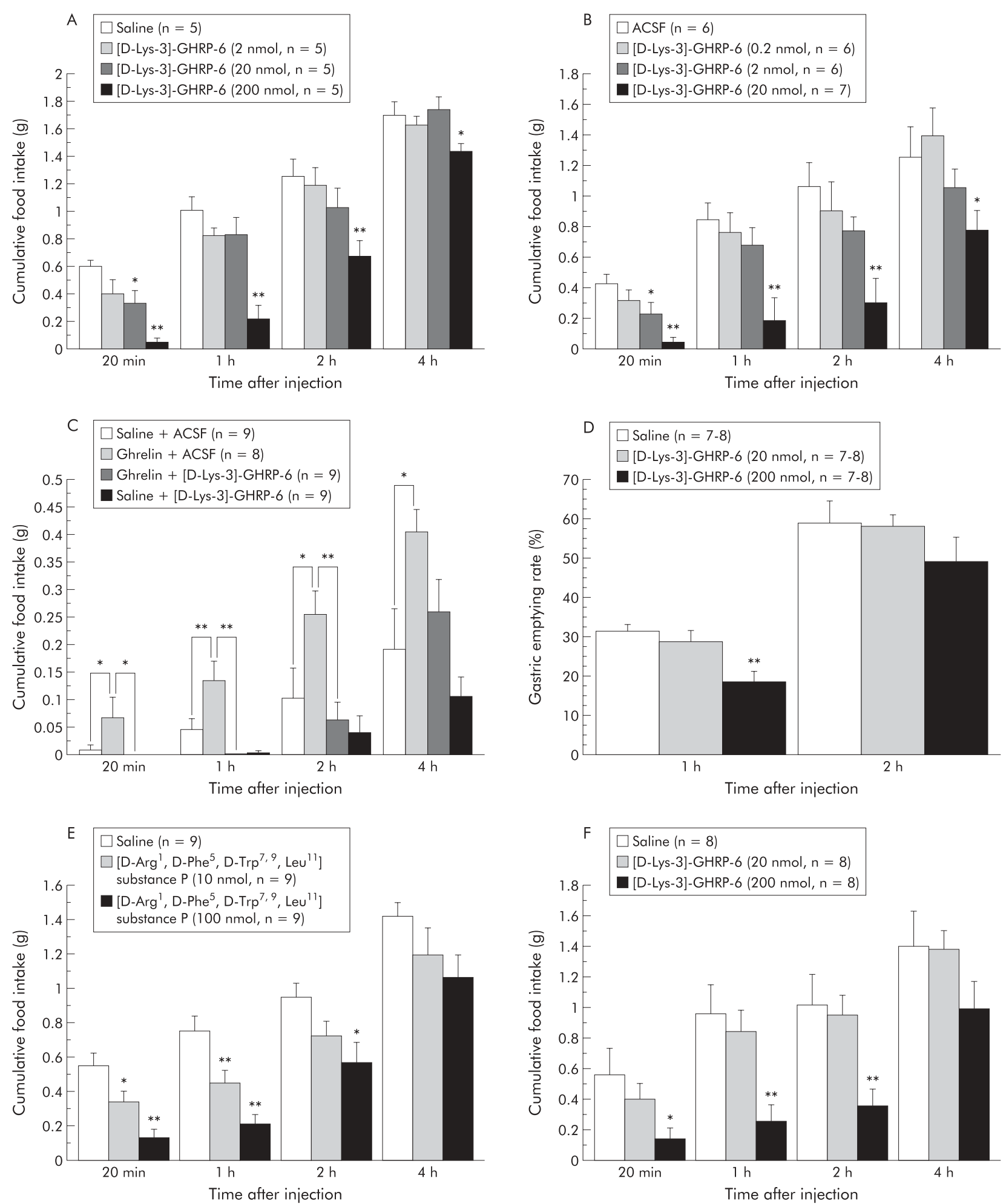

Figure 2 (A) Effects of intraperitoneally administered [D-Lys-3]-GHRP-6 (2-200 nmol/mouse) on cumulative food intake in food deprived lean mice: ${ }^{\star} p<0.05,{ }^{*} p<0.01$ compared with the control group by Bonferroni's $t$ test. (B) Effects of intracerebroventricularly administered [D-Lys-3]-GHRP-6 (0.2-20 nmol/mouse) on cumulative food intake in food deprived lean mice. ACSF, artificial cerebrospinal fluid.

(C) Antagonistic effects of [D-Lys-3]-GHRP-6 administered intracerebroventricularly (20 nmol/mouse) on feeding induced by intraperitoneal injection of ghrelin (3 nmol/mouse) in non-food deprived lean mice. (D) Inhibitory effects of intraperitoneally administered [D-Lys-3]-GHRP-6 (20-200 nmol/mouse) on the gastric emptying rate one and two hours after injection in lean mice. (E) Effects of intraperitoneally administered [D-Arg-1, D-Phe-5, D- Trp-7, 9, Leu-11] substance P (10-100 nmol/mouse) on cumulative food intake in food deprived lean mice. (F) Effects of intraperitoneally administered [D-Lys-3]-GHRP-6 (20-200 nmol/mouse) on cumulative food intake in mice with diet induced obesity who received a high fat diet for two weeks.

saline treated ob/ob obese mice (fig 3C). Control and [D-Lys-3]-GHRP-6 treated animals exhibited no significant differences in water intake $(10.5(0.43(200 \mathrm{nmol}) \vee 10.7$ (0.43) $\mathrm{ml} /$ day (control); $\mathrm{n}=7$ ).

\section{DISCUSSION}

The pathophysiology of obesity is known to be sustained excess of nutrient intake over expenditure. It has been shown that a "Western diet" with a high fat content is associated with 

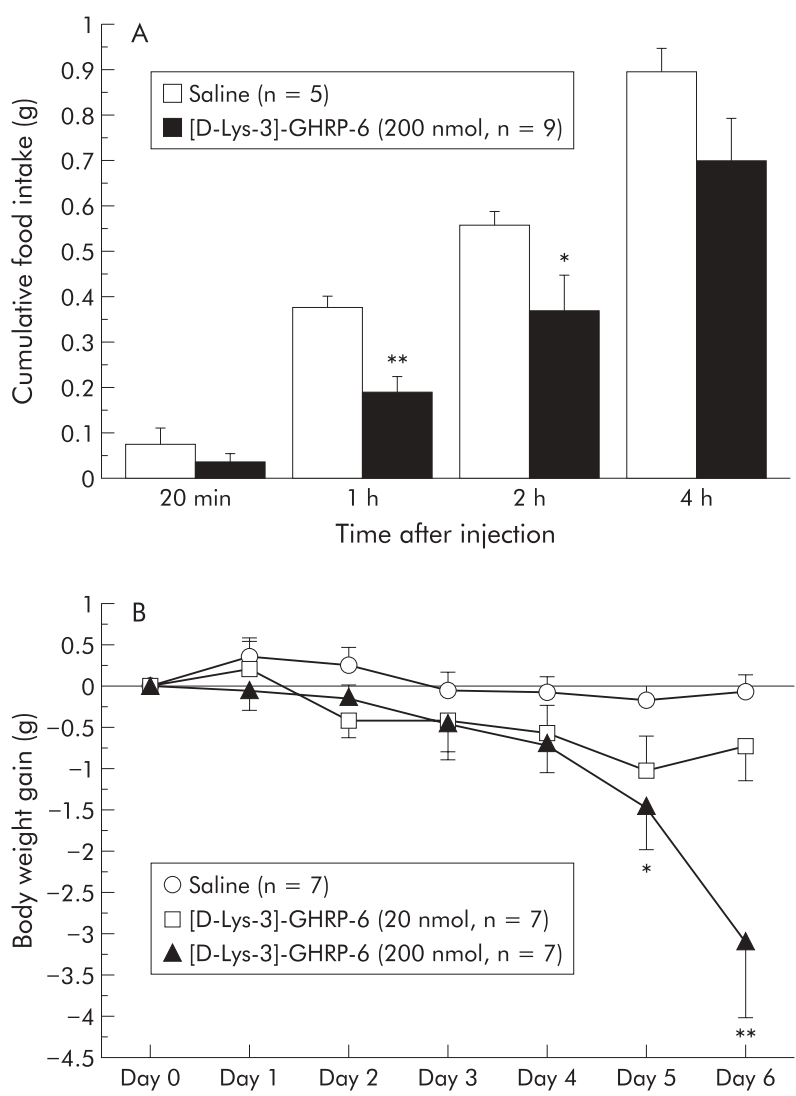

Figure 3 (A) Acute effects of intraperitoneally administered [D-Lys-3]-GHRP-6 (200 nmol/mouse) on cumulative food intake in food deprived ob/ob obese mice: ${ }^{*} p<0.05,{ }^{* *} p<0.01$ compared with physiological saline treated controls. (B) Chronic effects of [D-Lys- 3]-GHRP-6 administered intraperitoneally (20-200 $\mathrm{nmol} /$ mouse every 12 hours for six days) on body weight gain in non-food deprived ob/ob obese mice.

an increased risk of obesity. We previously reported that repeated administration of ghrelin significantly increased body weight compared with saline treated controls under a standard diet. ${ }^{4}$ Fat pad mass, serum insulin, and cholesterol levels showed a tendency to increase by $31.8 \%, 76.2 \%$, and $12.9 \%$, respectively, although they failed to reach statistical significance. In this study, we found that repeated administration of ghrelin significantly increased adiposity with a concomitant increase in cholesterol and insulin levels under a high fat diet.

Leptin, adiponectin, and resistin are known to be associated with insulin resistance as adipocytokines, in WAT. Leptin is thought to be a critical molecule in the body weight regulatory system as an adiposity signal from the periphery to the hypothalamus. ${ }^{214-16}$ On the other hand, previous studies have shown that hypoadiponectinaemia is closely related to hyperinsulinaemia and insulin resistance, which is ameliorated by adiponectin treatment. ${ }^{17}$ Resistin, a new adipose secreted polypeptide, has been reported to have a causative role in insulin resistance through an as yet unknown mechanism. ${ }^{18}$ However, this was recently challenged by conflicting data on resistin gene expression. While tumour necrosis factor $\alpha$ and FFA, which contribute to insulin resistance, have a suppressive effect on resistin mRNA levels in adipocytes, several types of peroxisome proliferator activated receptor gamma agonists, antidiabetic drugs with an insulin sensitising action, increase adipose resistin mRNA expression. ${ }^{19}{ }^{20}$ In addition, although serum levels of resistin are increased in genetic and diet induced forms of obesity, resistin gene expression is reported to be suppressed by insulin and obesity. ${ }^{18} 2122$ In the present study, ghrelin elevated leptin mRNA expression, as well as reduced resistin mRNA expression in WAT with insulin resistance, which might be compatible with the latter postulate. Recently, Lee et al have reported that under ad libitum fed condition, gastric ghrelin gene expression was decreased by a high fat diet. ${ }^{23}$ In contrast, we have shown here that under fasted condition, ghrelin gene expression in the stomach is increased by a high fat diet. These observations indicate that ghrelin appears to be closely related to excess weight gain, adiposity, and insulin resistance, particularly under a high fat diet and in the dynamic stage. If so, GHS-R may represent a target for pharmacological intervention in the treatment of obesity and related disorders.

Assuming that GHS-R antagonists would induce a state of negative energy balance, we examined the effects of GHS-R antagonists on feeding. As expected, GHS-R antagonists decreased feeding in lean mice and in mice rendered obese by a high fat diet. Previous reports have shown that GHS-R is present in the hypothalamus, heart, lung, pancreas, intestine, and adipose tissue. ${ }^{12}$ In the hypothalamus, GHS-R is located in the arcuate nucleus (ARC), where two orexigenic peptides, neuropeptide Y (NPY) and agouti related protein (AGRP), are synthesised in the neurone. ${ }^{12}{ }^{16}$ In addition, non-peptide GH secretagogues act in the hypothalamus to alter the electrical activity of ARC neurones and activate expression of c- fos. ${ }^{24} \mathrm{To}$ date, ghrelin has been reported to stimulate feeding behaviour with its mechanism of action involving direct activation of hypothalamic NPY and AGRP neurones in the ARC where the blood-brain barrier is less effective. ${ }^{24}{ }^{5}$ However, an alternative pathway for ghrelin signalling from the stomach is via an ascending neural network through the vagus nerve and brainstem nuclei that ultimately reaches the hypothalamus. ${ }^{2}$ In our study, centrally administered GHS-R antagonist abolished the stimulatory effects on feeding induced by peripherally

Table 2 Effects of [D-Lys-3]-GHRP-6 administered intraperitoneally (20-200 $\mathrm{nmol} /$ mouse every 12 hours for six days) on food intake, epididymal fat mass, gastrocnemius muscle, and blood glucose, insulin, cholesterol, triglyceride, and free fatty acid concentrations in ob/ob obese mice

\begin{tabular}{|c|c|c|c|}
\hline & Saline & $20 \mathrm{nmol}$ & $200 \mathrm{nmol}$ \\
\hline Food intake (g/day) & $4.845(0.160)$ & $4.527(0.261)$ & $4.285(0.298)$ \\
\hline Fat pad mass (g) & $0.974(0.066)$ & $0.897(0.169)$ & $0.860(0.086)$ \\
\hline Skeletal muscle (g) & $0.300(0.012)$ & $0.314(0.009)$ & $0.326(0.013)$ \\
\hline Glucose (mmolli) & $13.01 \quad(1.538)$ & $12.06 \quad(1.549)$ & $7.489(1.081)$ * \\
\hline Insulin (pmol/1) & $8294 \quad(1676)$ & $6242 \quad(1628)$ & $5481 \quad(1304)$ \\
\hline Cholesterol (mmol/1) & $6.649(0.346)$ & $5.663(0.291)$ & $5.906(0.565)$ \\
\hline Triglycerides (mmol/l) & $0.518(0.049)$ & $0.436(0.040)$ & $0.465(0.068)$ \\
\hline Free fatty acids (meq/l) & $2.164(0.075)$ & $2.036(0.121)$ & $1.646(0.078)^{* *}$ \\
\hline
\end{tabular}

${ }^{*} p<0.05,{ }^{* *} p<0.01$ compared with physiological saline treated controls. 
administered ghrelin. These results suggest that ghrelin may act through GHS-R in the brain. We also demonstrated that peripherally administered GHS-R antagonist decreased gastric emptying rate which may contribute to its anorexigenic effect. Considerable evidence has accumulated to indicate that gastric distention acts as a satiety signal to inhibit food intake, and rapid gastric emptying is closely related to overeating and obesity, as is delayed gastric emptying to anorexia and cachexia. ${ }^{25}$ Previous studies have shown that ghrelin increases gastric emptying rate and motility through vagal pathways. ${ }^{2}$ In addition, ICV administered NPY affects gastroduodenal contractile activity, changing fed patterns of irregular contractions into phasic contractions characterised as fasted patterns. ${ }^{26}$ Thus our findings suggest that GHS-R has a role in the control of feeding behaviour and that antagonism of GHS-R may be a promising approach for treating obesity.

Finally, we demonstrated that peripherally administered GHS-R antagonists produced anorexigenic effects and lowered body weight gain and blood glucose concentrations in ob/ob obese mice, which is a known genetic model of obesity and diabetes with insulin resistance and rapid gastric emptying. ${ }^{16}$ This remarkable reduction in glucose levels, accompanied by a moderate decrease in serum insulin levels, implicates GHS-R antagonists in the amelioration of insulin resistance. In contrast, it has been shown that elevations of plasma FFA induce insulin resistance through inhibition of glucose transport activity with its mechanism of action involving reduction of phosphatidylinositol 3-kinase activity. ${ }^{27}$ Recently, elevated circulating FFA concentration has been reported to be an independent risk factor for sudden death in middle aged men in a long term cohort study. ${ }^{28}$ In the present study, GHS-R antagonists produced a remarkable decrease in FFA levels of $o b / o b$ obese mice. In addition, GHS-R antagonists demonstrated no significant effects on water intake, general behaviour, or anxiety, compared with saline treated controls, suggesting the specific nature of the effect.

In conclusion, we found that peripherally administered GHS-R antagonists [D-Lys-3]- GHRP-6 and [D-Arg-1, D-Phe-5, D-Trp-7, 9, Leu-11] substance P decreased food intake in lean mice, in mice with diet induced obesity, and in $o b / o b$ obese mice. We also showed that repeated administration of [D-Lys-3]-GHRP-6 decreased body weight gain and improved glycaemic control in $o b / o b$ obese mice. In contrast, repeated administration of ghrelin, an endogenous ligand for GHS-R, induced remarkable adiposity and affected glycaemic control under a high fat diet. Moreover, gastric ghrelin gene expression during fasting was elevated by a high fat diet. Together with the findings that the stomach is not only a source of ghrelin but also a source of leptin, ${ }^{29}$ the stomach as well as adipose tissue plays a crucial role in the regulation of energy balance as an endocrine organ. Hansen et al have recently reported that weight loss in obese human subjects increases fasting plasma ghrelin levels. ${ }^{30}$ Moreover, transgenic rats expressing an antisense GHS-R mRNA have been reported to exhibit lower body weight and less adipose tissue than control rats. ${ }^{31}$ Although further studies are needed to determine the possibility of GHS-R antagonists acting as toxins, these observations suggest that gastric peptide ghrelin and GHS-R may be promising targets for pharmacological intervention, not only in the treatment of anorexia-cachexia but also in the treatment of obesity and type 2 diabetes, which are increasingly prevalent in the world.

\section{Authors' affiliations}

A Asakawa, A Inui, T Kaga, M Kasuga, Division of Diabetes, Digestive and Kidney Diseases, Department of Clinical Molecular Medicine, Kobe University Graduate School of Medicine, Kobe 650-0017, Japan

G Katsuura, Shionogi Research Laboratories, Shionogi and Co Ltd, Shiga 520-3423, Japan

M Fujimiya, Department of Anatomy, Shiga University of Medical
Science, Shiga 520-2192, Japan

M A Fujino, First Department of Internal Medicine, Yamanashi Medical University, Yamanashi 409-3898, Japan

\section{REFERENCES}

1 Kojima M, Hosoda H, Date Y, et al. Ghrelin is a

growth-hormone-releasing acylated peptide from stomach. Nature 1999;402:656-60

2 Invi A. Ghrelin: an orexigenic and somatotrophic signal from the stomach. Nat Rev Neurosci 2001;2:551-60.

3 Tschop M, Smiley DL, Heiman ML. Ghrelin induces adiposity in rodents. Nature 2000;407:908-13

4 Asakawa A, Inui A, Kaga T, et al. Ghrelin is an appetite-stimulatory signal from stomach with structural resemblance to motilin. Gastroenterology 2001;120:337-45.

5 Nakazato $M$, Murakami N, Date Y, et al. A role for ghrelin in the central regulation of feeding. Nature 2001;409:194-8

6 Wren AM, Seal L, Cohen MA, et al. Ghrelin enhances appetite and increases food intake in humans. J Clin Endocrinol Metab 2001;86:5992-5

7 Asakawa A, Inui A, Kaga T, et al. A role of ghrelin in neuroendocrine and behavioral responses to stress in mice. Neuroendocrinology 2001;74:143-7.

8 Cummings DE, Purnell JQ, Frayo RS, et al. A preprandial rise in plasma ghrelin levels suggests a role in meal initiation in humans. Diabetes 2001;50:1714-19.

9 Shiiya T, Nakazato M, Mizuta M, et al. Plasma ghrelin levels in lean and obese humans and the effect of glucose on ghrelin secretion. J Clin Endocrinol Metab 2002;87:240-4.

10 Cheng K, Chan WW, Barreto A, et al. The synergistic effects of His-D-Trp-Ala-Trp- D-Phe-Lys-NH2 on growth hormone (GH)-releasing factor-stimulated GH release and intracellular adenosine 3' $5^{\prime}$-monophosphate accumulation in rat primary pituitary cell culture. Endocrinology 1989;124:2791-8.

11 Veeraragavan K, Sethumadhavan K, Bowers CY. Growth hormone-releasing peptide (GHRP) binding to porcine anterior pituitary and hypothalamic membranes. Life Sci 1992;50:1149-55.

12 Cheng K, Wei L, Chaung LY, et al. Inhibition of L-692,429-stimulated rat growth hormone release by a weak substance $\mathrm{P}$ antagonist: L-756,867. J Endocrinol 1997:152:155-8.

13 Asakawa A, Inui A, Momose $\mathrm{K}$, et al. Endomorphins have orexigenic and anxiolytic activities in mice. Neuroreport 1998:9.2265-7.

14 Flier JS, Flier EM. Obesity and the hypothalamus: Novel peptides for new pathways. Cell 1998;92:437-40.

15 Kalra SP, Dube MG, Pu S, et al. Interacting appetite-regulating pathways in the hypothalamic regulation of body weight. Endocr Rev 1999;20:68-100.

16 Invi A. Transgenic approach to the study of body weight regulation. Pharmacol Rev 2000;52:35-61.

17 Yamauchi T, Kamon J, Waki H, et al. The fat-derived hormone adiponectin reverses insulin resistance associated with both lipoatrophy and obesity. Nat Med 2001;7:941-6.

18 Steppan CM, Bailey ST, Bhat S, et al. The hormone resistin links obesity to diabetes. Nature 2001:409:307-12.

19 Fasshauer M, Klein J, Neumann S, et al. Tumor necrosis factor alpha is a negative regulator of resistin gene expression and secretion in 3T3-L1 adipocytes. Biochem Biophys Res Commun 2001;288:1027-31.

20 Juan CC, Au LC, Fang VS, et al. Suppressed gene expression of adipocyte resistin in an insulin-resistant rat model probably by elevated free fatty acids. Biochem Biophys Res Commun 2001;289:1328-33.

21 Fujita $\mathbf{H}$, Fujishima $\mathrm{H}$, Morii T, et al. Effect of metformin on adipose tissue resistin expression in $\mathrm{db} / \mathrm{db}$ mice. Biochem Biophys Res Commun 2002;298:345-9.

22 Way JM, Gorgun CZ, Tong $Q$, et al. Adipose tissue resistin expression is severely suppressed in obesity and stimulated by peroxisome proliferator-activated receptor gamma agonists. J Biol Chem 2001;276:25651-3.

23 Lee HM, Wang G, Englander EW, et al. Ghrelin, a new gastrointestinal endocrine peptide that stimulates insulin secretion: enteric distribution, ontogeny, influence of endocrine, and dietary manipulations. Endocrinology 2002;143:185-90.

24 Lawrence CB, Snape AC, Baudoin FM, et al. Acute central ghrelin and $\mathrm{GH}$ secretagogues induce feeding and activate brain appetite centers. Endocrinology 2002;143:155-62.

25 Invi A. Cancer anorexia-cachexia syndrome: Current issues in research and management. CA-Cancer J Clin 2002;52:72-91.

26 Fujimura $M$, Inui A. Peptidergic regulation of gastrointestinal motility in rodents. Peptides 2000;21:1565-82.

27 Dresner A, Laurent D, Marcucci M, et al. Effects of free fatty acids on glucose transport and IRS-1 -associated phosphatidylinositol 3-kinase activity. J Clin Invest 1999:103:253-9.

28 Jouven X, Charles MA, Desnos $M$, et al. Circulating nonesterified fatty acid level as a predictive risk factor for sudden death in the population. Circulation 2001;104:756-61

29 Bado A, Levasseur S, Attoub S, et al. The stomach is a source of leptin Nature 1998;394:790-2.

30 Hansen TK, Dall R, Hosoda $\mathrm{H}$, et al. Weight loss increases circulating levels of ghrelin in human obesity. Clin Endocrinol 2002;56:203-6.

31 Shuto Y, Shibasaki T, Otagiri A, et al. Hypothalamic growth hormone secretagogue receptor regulates growth hormone secretion, feeding, and adiposity. J Clin Invest 2002;109:1429-36. 